HELMINTHOLOGIA, 58, 4: 385 - 393, 2021

\title{
Molecular and morphological characterization of the root-lesion nematode, Pratylenchus neglectus, on corn from Henan Province of China
}

\author{
Y. H. XIA', Y. K. LIU', P. H. HAO', H. X. YUAN', K. WANG ${ }^{1}$, H. L. LI ${ }^{1,2}$, Y. LI', 2,*

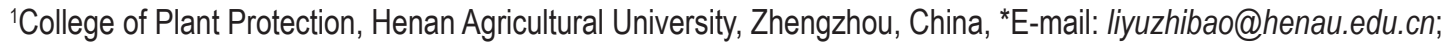 \\ ${ }^{2}$ National Key Laboratory of Wheat and Maize Crop Science, Zhengzhou, China
}

Article info

Received May 1, 2021

Accepted October 29, 2021

\section{Summary}

Root-lesion nematodes, Pratylenchus spp., are economically important pathogens because of their detrimental and economic impact on a wide range of crops. In August 2018, two samples of both roots and rhizosphere soil were collected from a corn field in Liangyuanqu of Shangqiu city, Henan Province, China. Root-lesion nematodes were recovered from the roots and soil samples using the modified Baermann funnel extraction method. Both the morphological characters and molecular analysis of the internal transcribed spacer (ITS) and D2-D3 expansion region of 28S ribosomal RNA sequences confirmed that the root-lesion nematode population collected from corn in this study was $P$. neglectus. Phylogenetic analyses showed that this isolate formed a highly supported clade with other $P$. neglectus isolates. To the best of our knowledge, this is the first report of $P$. neglectus on corn in Henan Province of China. This study reports the first partial sequences of 28S D2-D3 region of $P$. neglectus on corn in China. Due to the great harmfulness of root-lesion nematodes to corn, care should be taken to prevent the spread of $P$. neglectus to other regions in China. At the same time, further study on the biological characteristics of $P$. neglectus is needed, which will be helpful to develop corresponding management and control strategies.

Keywords: Corn (Zea mays); Root-lesion nematodes; Identification; Phylogeny; Pratylenchus neglectus

\section{Introduction}

Corn (Zea mays L.) is a very important cereal crop and serves as food, feed, and industrial material, with 45.0 million hectares planting areas in China (Liu et al., 2016; Qiu et al., 2020). Henan province is the main agricultural producing area in China and occupies an important position in the development of national economy. Root-lesion nematodes (Pratylenchus spp.) are migratory endoparasitic nematodes, which together with root-knot and cyst nematodes are three of the most economically important groups of plant parasitic nematodes species in the world (Castillo \& Vovlas, 2007). Root-lesion nematodes have a wide geographical distribution and can parasitize a wide range of host plants. Within the genus Pratylenchus, more than 100 species were recognized worldwide (Janssen et al., 2017). Corn is seriously attacked by several Pratylenchus species, including $P$. neglectus, $P$. scribneri, $P$. brachyurus, $P$. penetrans and $P$. zeae in the major production areas, causing significant economic losses (Windham, 1998). Infected roots of corn show dark brown discrete lesions that can serve as secondary infection sites for root-rotting fungi (Jones et

\footnotetext{
* - corresponding author
} 
al., 2013). P. neglectus Filipjev and Schuurmans Stekhoven, 1941 is widely distributed and has been reported on all continents except Antarctica (Castillo \& Vovlas, 2007).

More research suggests that the use of a small set of morphological features increases the risk of misidentification (Handoo et al., 2016; Wang et al., 2016). Thus, molecular approaches and phylogenetic analyses tools will allow more accurate nematode identification, regardless of developmental stage (Handoo et al., 2016). In this study, root-lesion nematodes were extracted from corn samples, and one individual female nematode was selected to propagate on carrot disks at $25{ }^{\circ} \mathrm{C}$ by parthenogenesis. The purified root-lesion nematode population was identified based on morphological and molecular analysis of the ITS rRNA gene and D2-D3 expansion region of 28S rRNA gene. Both morphological and molecular data confirmed the presence of $P$. neglectus. $P$. neglectus has only been reported on corn in Shandong province
(Qiu et al., 2016) and Tibet of China (Yu et al., 2017), however, only morphological identification was performed and the relevant molecular data was lacking. To the best of our knowledge, this is the first report of $P$. neglectus on corn in Henan province of China. It is also the first molecular data obtained from $P$. neglectus on corn in China. This study aimed to confirm the species of the root-lesion nematode occurred in Henan province of China.

\section{Methods and Materials}

Nematode sampling, extraction, and propagation

In August 2018, two samples of both roots and corresponding rhizosphere soils were collected from a corn field, near Liangyuan district of Shangqiu city, Henan Province, China (N 32 ${ }^{\circ} 16^{\prime} 16.50^{\prime \prime}$, E $115^{\circ} 38^{\prime} 9.48^{\prime \prime)}$. Root-lesion nematodes were extracted using the modified Baermann funnel method for 2 days (Hooper et al.,

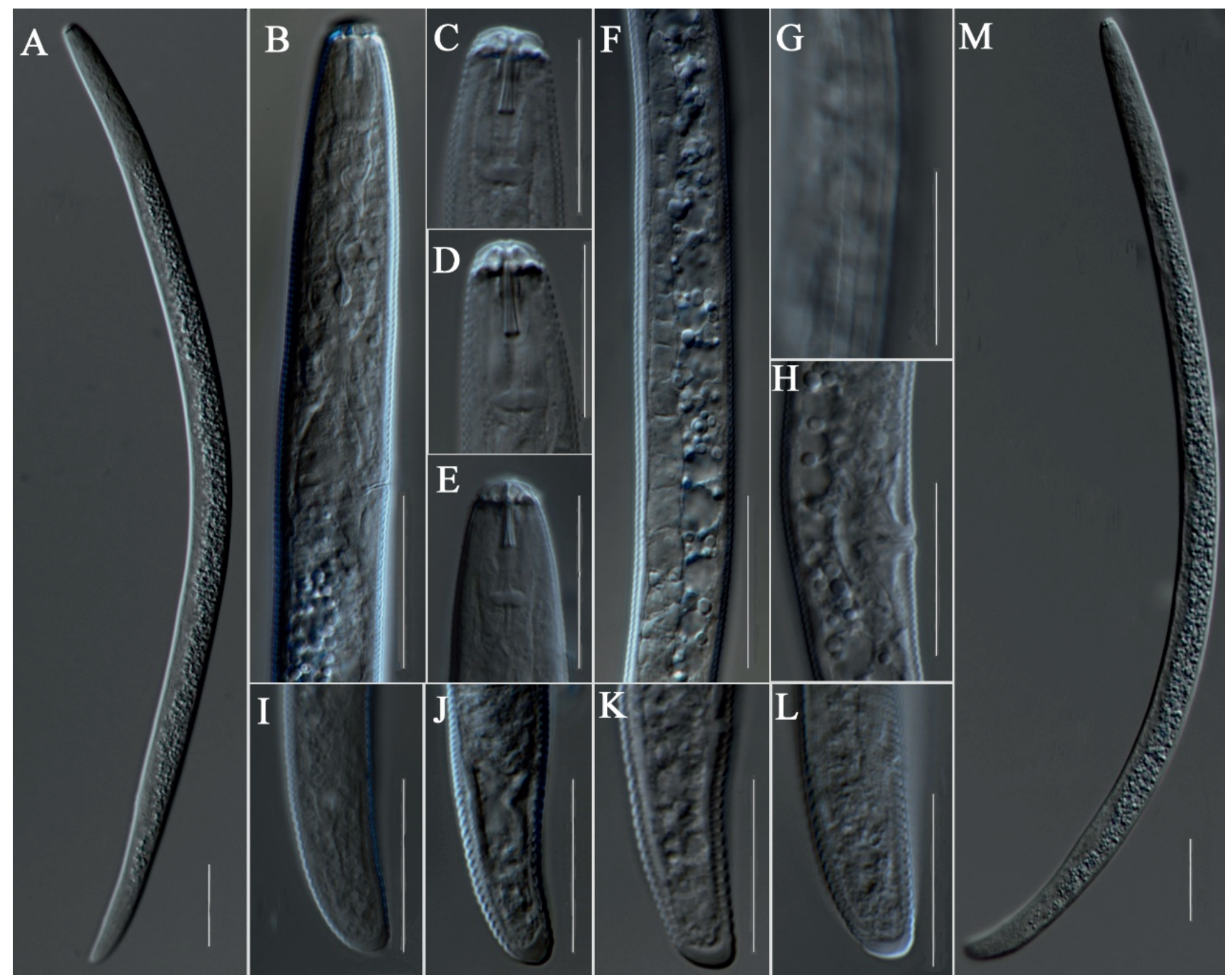

Fig. 1. Light micrographs of Pratylenchus neglectus from corn in Henan Province of China. Females (A -M): A and M, Entire body; B: Anterior region; C-E: lip region; F: Anterior end of genital gland; G: Lateral line; H: Post-vulval region and ovary; I-L: tail region. Scale bars: $50 \mu \mathrm{m}(\mathrm{A}, \mathrm{M})$ and $20 \mu \mathrm{m}(\mathrm{B}-\mathrm{L})$. 
Table 1. Measurements of the Pratylenchus neglectus population morphological characteristics.

\begin{tabular}{|c|c|c|c|}
\hline Character & SY-X & Pourjam et al. (1999) & Ryss (1988) \\
\hline$n$ & 16 & 32 & 10 \\
\hline $\mathrm{L}$ & $459.0 \pm 23.0(431.0-498.0)$ & $490(300-590)$ & $600(410-700)$ \\
\hline a & $22.9 \pm 1.6(20.0-26.1)$ & $26.7(22.3-32.2)$ & $24(17-31)$ \\
\hline$b$ & $5.7 \pm 0.5(5.0-6.6)$ & $6.0(4.3-7.6)$ & $6.3(4.9-7.1)$ \\
\hline$b^{\prime}$ & $4.3 \pm 0.3(3.9-4.7)$ & $4.3(3.4-5.2)$ & - \\
\hline$c$ & $18.7 \pm 2.2(15.2-24.7)$ & $21.4(14.8-28.2)$ & $21(13-31)$ \\
\hline$c^{\prime}$ & $2.1 \pm 0.3(1.5-2.6)$ & $2.1(1.5-3.0)$ & $1.9(1.5-2.5)$ \\
\hline v & $80.5 \pm 2.1(77.5-84.6)$ & $82(80-85)$ & $83(77-85)$ \\
\hline Stylet length & $15.8 \pm 1.1(14.3-17.4)$ & $16(14-18)$ & $16(15.5-17.5)$ \\
\hline Stylet shaft & $8.1 \pm 0.5(7.3-9.3)$ & - & - \\
\hline Stylet knob width & $4.1 \pm 0.4(3.2-4.8)$ & - & - \\
\hline Stylet knob height & $2.0 \pm 0.3(1.6-2.7)$ & - & - \\
\hline DGO from stylet base & $2.5 \pm 0.5(1.4-3.3)$ & - & - \\
\hline center of metacorpus & $45.7 \pm 2.7(40.3-50.5)$ & - & - \\
\hline end of pharyngeal gland lobe & $107.0 \pm 4.3(98.5-113.0)$ & - & - \\
\hline Anterior end to excretory pore & $74.5 \pm 4.5(68.5-85.0)$ & - & - \\
\hline Pharyngeal overlap & $26.7 \pm 4.9(19.6-39.4)$ & - & - \\
\hline Max body diam. & $20.1 \pm 1.6(17.8-23.7)$ & - & - \\
\hline Vulval body diam. & $17.9 \pm 1.2(16.0-20.00)$ & - & - \\
\hline Anal body diam. & $12.0 \pm 1.1(10.6-14.8)$ & - & - \\
\hline Anterior genital trace length & $147.4 \pm 21.9(102.8-192.7)$ & - & - \\
\hline Tail length & $24.8 \pm 2.4(20.0-29.0)$ & - & - \\
\hline No. of tail annuli & $20.7 \pm 2.3(18-24)$ & - & - \\
\hline Vulva to annus distance & $68.0 \pm 11.5(53.5-96.5)$ & - & - \\
\hline Post- uterine sac length & $19.7 \pm 4.2(13.0-21.7)$ & - & - \\
\hline Lateral field width & $7.2 \pm 1.1(5.8-8.8)$ & - & - \\
\hline Lip width & $8.1 \pm 0.4(7.1-8.6)$ & - & - \\
\hline Lip height & $2.4 \pm 0.4(1.7-3.1)$ & - & - \\
\hline
\end{tabular}

Note: All measurements are in $\mu \mathrm{m}$ and in the form of mean $\pm \mathrm{SD}$ (range). $\mathrm{n}$ : Number of specimens measured; L: Body length; a: Body length/greatest body width; $b$ : Body length/length from the lips to the junction of esophageal gland and intestine; b': Body length/ length from the lips to esophageal gland end; c: Body length/ tail length; c': Tail length/tail diameter at anus; V: Distance of vulva from the lips×100/body length; DGO: Distance between dorsal esophageal gland opening and stylet knobs.

2005), by which $100 \mathrm{~g}$ of corn soil and roots samples were extracted from each sample. One individual female nematode was picked out and sterilized with $0.3 \%$ streptomycin sulfate, and then transferred to carrot disks at $25{ }^{\circ} \mathrm{C}$ for 15 weeks in the dark for propagation (Li et al., 2019; Wang et al., 2021). After that, purified root-lesion nematodes cultured on carrot disks were extracted and used for morphological and molecular analysis (Xia et al., 2021).

\section{Morphological identification}

Root-lesion nematodes were fixed in $4 \%$ formaldehyde and pro- 
cessed to glycerin by the formalin glycerin method (Hooper, 1970; Golden, 1990). Photomicrographs and morphometric data of the specimens were obtained using a Nikon Eclipse Ti-S microscope equipped with a Nikon DS-Ri2 camera (Nikon, Tokyo, Japan). Images of key morphological features were processed using Photoshop CS5. Morphometric ratios were performed as defined by De Man. All measurements were expressed in micrometers $(\mu \mathrm{m})$, unless otherwise stated.

\section{DNA extraction, PCR, and sequencing}

DNA was extracted from individual live root-lesion nematode and followed by proteinase K-based lysis (Wang et al., 2011). The rRNA-internal transcribed spacer (ITS) region and D2-D3 expansion region of the 28S rRNA were amplified with primers TW81/ AB28 (5'-GTTTCCGTAGGTGAACCTGC-3'/5'-ATATGCTTAAGTTCAGCGGGT-3') (Subbotin et al., 2006) and primers D2A-D3B (5'-ACAAGTACCGTGAGGGAAAGTTG-3'/5'-TCGGAAGGAACCAGCTACTA-3') (De Ley et al., 1999), respectively. The reaction system was prepared according to the instructions of KOD FX DNA polymerase (TOYOBO, Japan). The thermocycler conditions for amplification comprised initial denaturation at $95^{\circ} \mathrm{C}$ for $2 \mathrm{~min}$, followed by 35 cycles of denaturation at $98^{\circ} \mathrm{C}$ for $10 \mathrm{~s}$, annealing for $30 \mathrm{~s}$ at $58.2^{\circ} \mathrm{C}$ for ITS and $51.7^{\circ} \mathrm{C}$ for $28 \mathrm{~S}$, extension at $68^{\circ} \mathrm{C}$ for $90 \mathrm{~s}$, and a final extension at $72^{\circ} \mathrm{C}$ for $10 \mathrm{~min}$. The PCR products were purified using the Biospin Gel Extraction Kit (BioFlux, China) and ligated into pJET1.2/blunt cloning vectors (Thermo Scientific, USA) and transformed to Escherichia coli strain DH5a, and then sequenced by Sangon Biotech Co. Ltd (Shanghai, PR China). The obtained ITS sequences and D2-D3 expansion region of $28 \mathrm{~S}$ rRNA sequences in this study were submitted to GenBank database.

\section{Sequencing analysis and phylogenetic relationships}

The obtained ITS sequences and D2-D3 expansion region of 28S rRNA sequences were compared with other nematode species sequences available in the GenBank database using the BLAST homology search tool (https://blast.ncbi.nlm.nih.gov/Blast.cgi). Multiple alignments of the nematode rRNA-ITS and rRNA $28 \mathrm{~S}$ D2-D3 sequence were performed using Clustal W in MEGA 7 (Tamura et al., 2011). Phylogenetic analysis of the sequence dataset was conducted by Bayesian inference (BI) using MrBayes 3.2.6 (Huelsenbeck \& Ronquist, 2001). The best-fit model of nucleotide evolution was determined with MrModeltest 2.3 (Nylander, 2004) to be $G T R+\mid+G$, according to Akaike Information Criteria (AIC). Bayesian analysis was run with random starting trees, four Markov chains for $1 \times 10^{6}$ generations, with Markov chains sampled every 100 generations. Two runs were performed for each analysis. Outgroups were selected based on the previous reports (Subbotin et al., 2008; Wang et al., 2015). After discarding burn-in samples, the remaining samples were used to generate a $50 \%$ majority rule consensus tree. Posterior probabilities (pp) were given on appropriate clades.

\section{Ethical Approval and/or Informed Consent}

This article does not contain any studies with human participants or animals by any of the authors.

\section{Results}

\section{Morphology of the root-lesion nematodes}

The morphology of the root-lesion nematodes SY-X population isolated from corn in this study was photographed (Fig. 1). The morphometric measurements of the SY-X population of $P$. neglectus (Table 1) were consistent with $P$. neglectus as described previously (Ryss, 1988; Pourjam et al., 1999; Castillo \& Vovlas, 2007). Female: The body vermiform, straight or slightly ventrally curved after heat-killing (Fig. 1A, M); Labial region bluntly rounded, with two annuli, anterior one distinctly narrower than second, apical one comprising the lips (Fig. 1C, D, E); Stylet is robust, with rounded knobs that vary little in shape and typically indented on anterior surfaces, stylet length $14.3-17.4 \mu \mathrm{m}$ (Fig. 1C, D, E); Lateral field composed of four lines at midbody (Fig. 1G); Pharyngeal gland overlapping intestine ventrally or ventrolaterally (Fig. 1B); Excretory pore $69-85 \mu \mathrm{m}$ from anterior end. Hemizonid just anterior to the excretory pore, extending over $2-3$ body annules (Fig. 1B); Female monodelphic, prodelphic, ovary outstretched with oocytes in tandem (Fig. 1F); Post-vulval uterine sac equal to or less than body diameter, $13-21.7 \mu \mathrm{m}$ long and normally undifferentiated (Fig. 1H); Tail variable in shape, usually conoid with little curvature

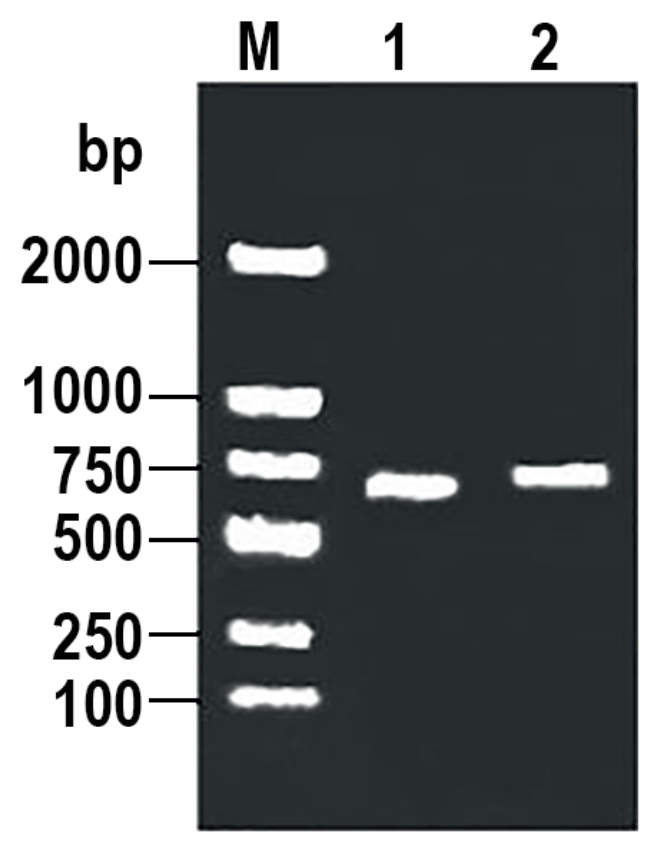

Fig. 2. PCR amplification of the rDNA-ITS and rDNA 28S D2-D3 expansion region of Pratylenchus neglectus. M: DL2000 Marker; 1: rDNA-ITS; 2: D2-D3 expansion region of the $28 \mathrm{~S}$ rDNA. 


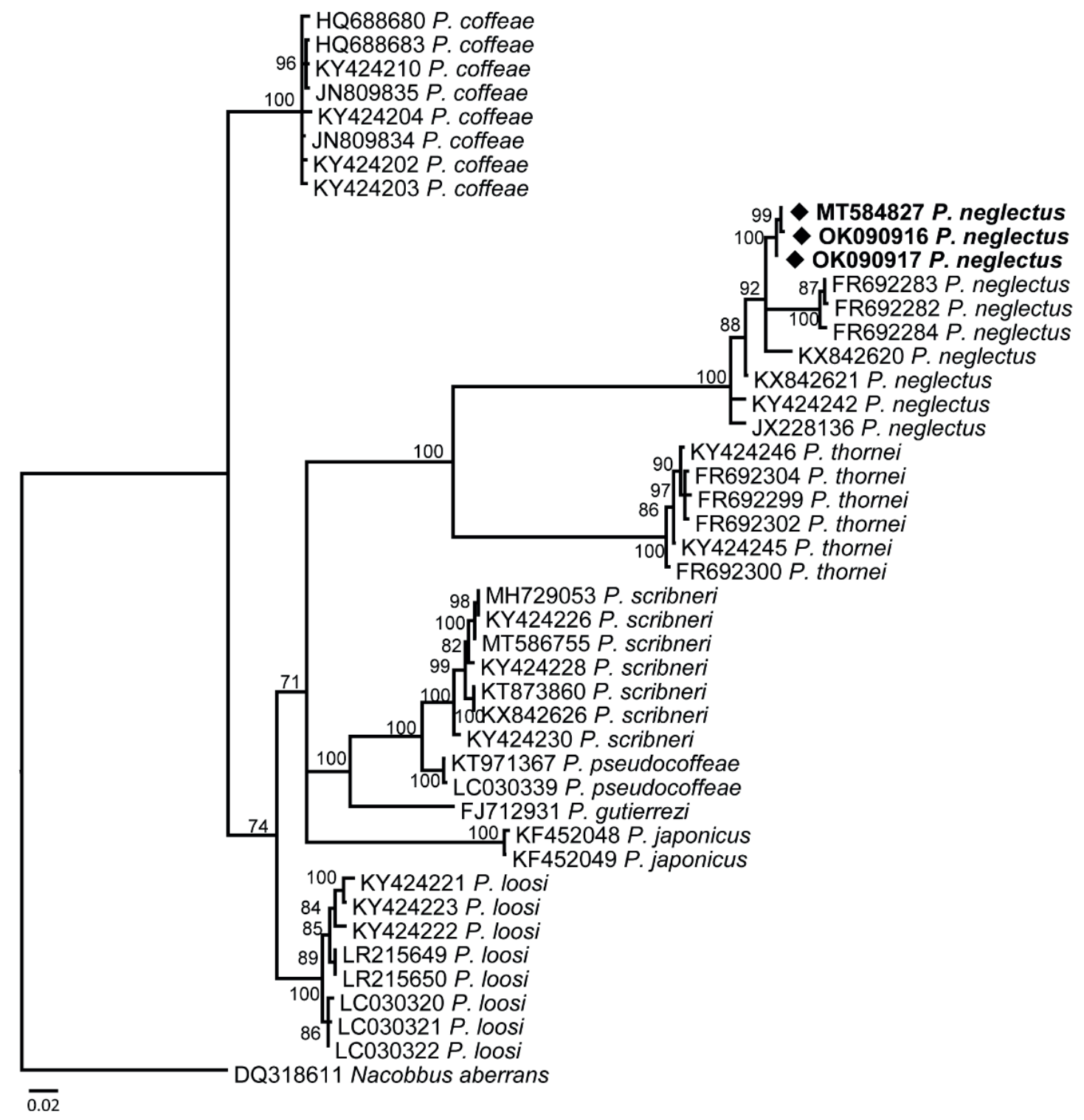

Fig. 3. Bayesian tree of Pratylenchus as inferred from rDNA-ITS sequences under GTR+I+G model. Posterior probabilities more than $50 \%$ are given for appropriate clades. Newly obtained sequence is indicated in bold font.

of ventral surface and usually with $18-24$ annuli. Tail terminus without annulation, usually rounded, but may be obliquely truncate or slightly digitate (Fig. 1I, J, K, L). The main morphological features of the SY-X population correspond well with those of other Chinese populations of $P$. neglectus (Yu et al., 2017; Li et al., 2018).

Male: Not found.

Molecular characterization and phylogenetic relationships of $P$. neglectus

PCR amplification of the ITS rRNA region of $P$. neglectus populations yielded a single product with a length of $689 \mathrm{bp}$ (Fig. 2).
The obtained ITS sequences of the root-lesion nematode collected in this study (MT584827, OK090917 and OK090916) showed $99 \%$ identity with $P$. neglectus sequence available from GenBank (HM469449) and the differences was $3-29$ bp between the newly obtained sequences and the sequences of $P$. neglectus from GenBank. Amplification of the D2-D3 region of 28S rRNA gene of $P$. neglectus yielded a PCR fragment of $781 \mathrm{bp}$ (Fig. 2). The obtained 28S sequences (MT584828, OK094022 and OK094021) had $100 \%$ identity with several $P$. neglectus sequences available in the GenBank (e.g., MG906760, MG906750, MW487243 and MG906749) and diversity within $P$. neglectus populations varied from 0 to 9 nucleotides. 


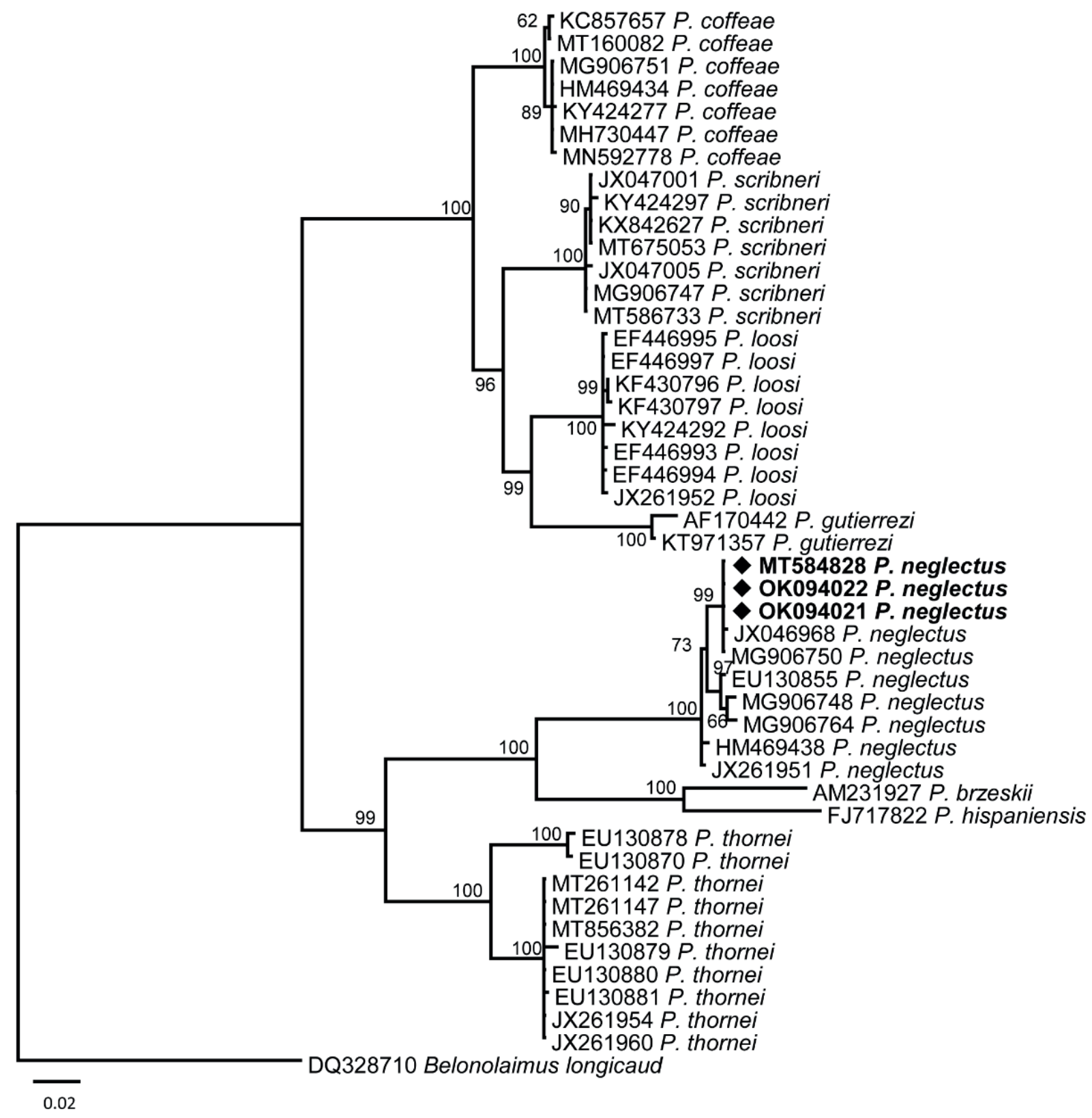

Fig. 4. Bayesian tree of Pratylenchus as inferred from rDNA 28S D2-D3 sequences under GTR+|+G model. Posterior probabilities more than $50 \%$ are given for appropriate clades. Newly obtained sequence is indicated in bold font.

The phylogenetic tree generated from rRNA ITS is presented in Figure 3, which contained 44 ingroups and one outgroup taxon. This tree showed that the newly obtained sequence of $P$. neglectus in this study (MT584827, OK090917 and OK090916) is clearly different from other Paratylenchus species ITS sequences, and formed a $100 \%$ supported clade with $P$. neglectus. The phylogenetic tree generated from $28 S$ D2-D3 region in Figure 4, contained 46 ingroups and one outgroup taxon. This tree indicated that the newly obtained sequence of $P$. neglectus in this study (MT584828,
OK094022 and OK094021) is clearly different from other Pratylenchus species 28S of D2-D3 region sequences in the GenBank, and formed a highly supported clade with $P$. neglectus (100\%). These results further confirmed that the root-lesion nematodes obtained in this study were $P$. neglectus.

\section{Discussion}

Despite the agricultural importance of some Pratylenchus spe- 
cies, information about these organisms of description is relatively scarce. In addition, identification of root-lesion nematodes must take into account countries and hosts, due to the presence of the intraspecific variation (Dobosz et al., 2013). Therefore, some descriptions of Pratylenchus species from new host are also available information.

The taxonomy of the genus Pratylenchus is always difficult due to intraspecific variability in the diagnostic characters and the overlap of many measurements and characters among different species (Ryss, 2002). Loof (1978) pointed out that a few characteristics were reliable and useful for differentiating Pratylenchus species, such as stylet length, structure of lateral fields, position of the vulva, head shape and shape of tail. In this study, the morphological identification of root-lesion nematodes collected from the corn rhizosphere soils and roots in Henan province of China was carried out. The main morphological characteristics of SY-X population of $P$. neglectus were compared with data of Pourjam et al. (1999) and Ryss (1988). We found the $c$ values of female nematodes was relatively the less than data of Pourjam et al. (1999) and Ryss (1988); $L$ and $b$ values of female nematodes were less than data of Ryss (1988); a value of female nematodes were slightly less than data of Pourjam et al. (1999). The reason for differences among different geographical isolates may be related to the small activity range and weak active dispersal ability of $P$. neglectus.

Nematode species difficult to distinguish morphologically from other species can be successfully identified using molecular identification. Hence, it is important to complement the specific identification with analysis of different molecular markers to reinforce the diagnosis (Lax et al., 2021). And molecular identification is also useful in resolving the possible existence of species complexes. In our study, molecular identification found the ITS and 28S rRNA region sequences were the highest identity with one population of $P$. neglectus and our phylogenetic analysis showed that these obtained sequences clustered within the strongly supported $P$. neglectus clade.

Plant parasitic nematodes are important pathogens of corn, and it has been reported that many plant parasitic nematodes can infect corn in several provinces of China (Qiu et al., 2017; Xu et al., 2012). P. neglectus is one of the most important root-lesion nematodes. It can infect Triticun aestivum, Zea mays, Glycine max, Helianthus annuus, Solanum tuberosum, Brassica oleracea, Lactuca sativa, Juglans regia, Cucunis sativus, Nicotiana tabacum, Gossypium sp., Brassica napus, Arachis hypogaea, Fragaria ananassa and other food and commercial crop in China (Liu \& Liu, 2007; Yu et al., 2017; Li et al., 2019). Additionally, P. neglectus is widely distributed in the world and has been reported to infect corn both in China and abroad (Castillo \& Vovlas, 2007). It has been recorded to infect corn in lowa, USA (Williams, 1982) and several European countries (Tacconi et al., 1988; Urek et al., 2013). P. neglectus has only been reported on corn in Shandong province (Qiu et al., 2016) and Tibet of China (Yu et al., 2017), however, only morphological identification was performed in these two reports and the relevant molecular data were lacking. Both morphological and molecular data confirmed the identity of $P$. neglectus on corn in Henan province of China in this study. As far as we know, this is the first report of $P$. neglectus on corn in Henan Province of China. It is also the first molecular data of 28S D2-D3 regions obtained from $P$. neglectus on corn in China. Detection of $P$. neglectus on corn is of great value for further study of their potential harm and control measures. Because the root-lesion nematode can cause great harm to corn, attention should be paid to prevent the spread of $P$. neglectus to other corn producing areas in China.

\section{Conflict of Interest}

The authors state no conflict of interest.

\section{Acknowledgments}

This study was financially supported by the Key Research and Development and Promotion of Special Scientific and Technological Projects in Henan Province (No. 202102110225), the Key Scientific Research Projects of Colleges and Universities in Henan Province of China (No. 21B210003) and Corn Industry Technology System Plant Protection Post Expert Scientific Research Special Project of Henan Province in China (S2015-02-G05).

\section{References}

Castillo, P., Vovlas, N. (2007): Pratylenchus (Nematoda: Pratylenchus): Diagnosis, biology, pathogenicity and management. Nematology monographs and perspectives, vol. 6. Leiden, The Netherlands: Brill. DOI: 10.1163/ej. $9789004155640 . i-523$

Dobosz, R., WiniszewsKa, G., MalewskI, T., RYbarczYK-MydŁowska, K., Tereba, A., Kowalewska, K., Gawlak, M., Bogdanowicz, W. (2013): Morphological and molecular features of Punctodera stonei Brzeski, 1998 (Nematoda: Heteroderidae) - species associated with roots of grasses. Ann Zoo, 63: 157-162. DOI: 10.3161/000345413X669487

De, L.P., Felix, M.A., Frisse, L.M., Steven, A.N. (1999): Molecular and morphological characterization of two reproductively isolated species with mirror-image anatomy (Nematoda: Cephalobidae). Nematology, 1: 591 - 612. DOI: 10.1163/156854199508559

Golden, A.M. (1990): Preparation and mounting nematodes for microscopic observation. In ZuCKeRMAn B.M., MAI W.F. And KRUSBERG L.R. (Eds) Plant nematology laboratory manual University of Massachusetts Agricultural Experiment Station, Amherst, MA, pp. $197-205$

Handoo, Z.A., Carta, L.K., Skantar, A.M., Subbotin, S.A., Fraedrich, S.W. (2016): Molecular and morphological characterization of Xiphinema chambersi population from live Oak in Jekyll Island, Georgia, with comments on morphometric variation. J. Nematol, 48: 20 - 27. DOI: 10.21307/jofnem-2017-005

Hooper, D.J., Hallmann, J., Subbotin, S.A. (2005): Methods for ex- 
traction, processing and detection of plant and soil nematodes. 53 - 86. In LUC, M., SIKORA, R.A., BRIDGE J. (Eds) Plant parasitic nematodes in subtropical and tropical agriculture. 2nd edn. UK, CABI Publishing. DOI: 10.1079/9780851997278.0053

HUELSENBECK, J.P., RonquIST, F. (2001): Mrbayes: Bayesian inference of phylogenetic trees. Bioinformatics, 17: $754-755$

HOOPER, D.J. (1970): Handling, fixing, staining, and mounting nematodes. In SouthEY, J.F. (Ed) Laboratory methods for work with plant and soil nematodes 5th ed., Her Majesty's Stationery Office, London, pp. $39-54$

Janssen, T., Karssen, G., Orlando, V., Subbotin, S.A. Bert, W. (2017): Molecular characterization and species delimiting of plant parasitic nematodes of the genus Pratylenchus from the penetrans group (Nematoda: Pratylenchidae). Mol. Phylogenet. Evol, 117: 30 - 48. DOI: 10.1016/j.ympev.2017.07.027

Jones, J.T., Haegeman, A., Danchin, E.G.J., Gaur, H.S., Helder, J., Jones, M.G.K., Kikuchl, T., Manzanilla-Lòpez, R., Palomares, J.E., Wesemael, W.M.L., Perry, R.N. (2013): Top ten plant-parasitic nematodes in molecular plant pathology. Mol. Plant Pathology, 14: $946-961$

Lax, P., Rondan, J.C., Andrade, A.J., Doucet, M.E. (2021): Punctodera achalensis n. sp. (Nematoda: Punctoderidae), a new cyst nematode from Argentina. Eur J Plant Pathol, 161: 397 - 409. DOI:10.1007/s10658-021-02331-7

LI, L., He, J., LIU, L.L., Gu, J.F., Zhang, J.G. (2018): Identification of Pratylenchus neglectus from sugarbeet in Xinjiang. Plant Quar, 32: 20-23. DOI: 10.19662/j.cnki.issn1005-2755.2018.02.007

LI, Y., Wang, S., Du, J., Lu, Q.S., Wang, Z.Y., Wang, K., LI, H.L. (2018): First report of the root-lesion nematode (Pratylenchus neglectus) on wheat in Anhui province, China. Plant Dis, 102: 5663 $-5663$

LI, Y., Wang, S., LIU, Y.K., LU, Q.S., WANG, K., LI, H.L. (2019): Occurrence of soybean root rot caused by Pratylenchus coffeae in Henan province, China. Plant Dis, 103: 1435 - 1435.

LIU, X.Y., LIU, W.Z. (2007): Species of nematodes of Pratylenchidae in Shandong province. Journal of Qingdao Agricultural University, 24(3): 175 - 176. DOI: 10.3969/j.issn.1674-148X.2007.03.006

Liu, Q.S., Hallerman, E., Peng, Y.F., LI, Y.H., Massimo, M., FrancESCA, B. (2016): Development of Bt rice and Bt maize in China and their efficacy in target pest control. Int. J. Mol. Sci, 17: 1561 - 1576. DOI: $10.3390 /$ ijms 17101561

Loof, P.A.A. (1978) The genus Pratylenchus Filipjev, 1936 (Nematoda: Pratylenchidae): a review of its anatomy, morphology, distribution, systematics and identification. Sveriges Landbruksuniversiteit Växtskyddsrapporter, 5, 1-12

Nylander, J.A.A. (2004): MrModeltest 2.3. Program distributed by the author, Evolutionary Biology Centre, Uppsala University, Uppsala, Sweden

QIU, H.G., LI, X.H., Yu, J.L. (2020): China maize industry: development trends and policy suggestions. Issues in Agricultural Economy, 7: 4 - 16. DOI: 10.13246/j.cnki.iae.2021.07.002

QuU, Z.Q., Mo, A.S., He, Q., Wu, H.Y., ZHou, X.B. (2016): Root-le- sion nematodes on maize in Shandong, China. J. Gen. Plant. Pathology, 82: 224 - 227. DOI: 10.1007/s10327-016-0660-0

QIU, Z.Q., Wu, H.Y., LoNG, Y.R. (2017): Research progress in the occurrence and biology of Heterodera zeae. Plant Protec, 43: 16 20. DOI: 10.3969/j.issn.0529-1542.2017.04.003

Pourjam, E., Kheiri, A., Geraert, E., Alizadeh, A. (1999): Variations in Iranian population of Pratylenchus neglectus and $P$. thornei (Nematoda: Pratylenchidae). Iran. J. Plant. Pathology, 35: 67

Ryss, A.Y. (1988): World fauna of the root parasitic nematodes of the family Pratylenchidae (Tylenchida). Leningrad, USSR, $367 \mathrm{pp}$ Ryss, A.Y. (2002): Genus Pratylenchus Filipjev: multientry and monoentry keys and diagnostic relationships (Nematoda: Tylenchida: Pratylenchidae). Zoosyst Ross, 10: 241 - 255

Subbotin. S.A., Ragsdale, E.J., Mullens, T., Roberts, P.A., Mundo, M., BALDWIN, J.G. (2008): A phylogenetic framework for root-lesion nematodes of the genus Pratylenchus (Nematoda): evidence from $18 \mathrm{~S}$ and D2-D3 expansion segments of 28S ribosomal RNA genes and morphological characters. Mol. Phylogenet. Evol, 48: 491 505. DOI: 10.1016/j.ympev.2008.04.028

Subbotin, S.A., Sturhan, D., Chizhov, V.N., Vovlas, N., BaldWIN, J.G. (2006): Phylogenetic analysis of Tylenchida Thorne, 1949 as inferred from D2 and D3 expansion fragments of the $28 \mathrm{~S}$ rRNA gene sequences. Nematology, 8(3), 455 - 474. DOI: $10.1163 / 156854106778493420$

Tacconi, R., SantI, R., Pola, R. (1988): Pratylenchus neglectus sugranturco (Zea mays) in Emilia Romagna. Infor Fitopatologico, 38: $59-61$

Tamura, K., Peterson, D., Peterson, N., Stecher, G., Nel, M., KuMAR, S. (2011): MEGA5: molecular evolutionary genetics analysis using maximum likelihood, evolutionary distance, and maximum parsimony methods. Mol Biol Evol, 28(10): 2731 - 2739

UREK, G., ŠIRCA, S., KARSSEN, G. (2003): A review of plant-parasitic and soil nematodes in Slovenia. Nematology, 5: 391 - 403. DOI: $10.1163 / 156854103769224386$

Wang, H., ZHuo, K., LIAO, J.L. (2016): Morphological and molecular characterization of Pratylenchus hippeastri, a new record of root-lesion nematode associated with apple in China. Pak. J. Zool, 48: $665-671$

Wang, H.H., Zhuo, K., Ye, W.M., LiaO, J.L. (2015): Morphological and molecular charaterisation of Pratylenchus parazeae n. sp. (Nematoda: Pratylenchidae) parasitizing sugarcane in China. Eur. J. Plant. Pathol, 143: 173 - 191. DOI: 10.1007/s10658-015-0674-z WANG, J.L., ZHANG, J.C., Gu, J.F. (2011): DNA extracted method on single nematode. Plant Quar, 25: 32 - 35. DOI: 10.19662/j.cnki. issn1005-2755.2011.02.009

Wang, K., HaO, P.H., LIU, Y.K, XIA, Y.H., Sun, B.J., LI, H.L., LI, Y. (2021): Occurrence of Pratylenchus coffeae causing root rot of soybean in Shandong province of China. Plant Dis, 2020. DOI: 10.1094/PDIS-08-20-1740-PDN

WilLlams, D.D. (1982): The known Pratylenchidae (Nematoda) of lowa. lowa. J. Res, 56: $419-424$

Windham, G.L. (1998): Corn. In: Barker, K.R., Pederson, G.A. \& 
Windham, G.L. (Eds) Plant and nematode interactions. Madison, WI, USA, American Society of Agronomy, Inc., Crop Science Society of America, Inc., Soil Science Society of America, Inc, pp. $335-357$

XIA, Y.H., LiU, Y.K, HaO, P.H., ZhaO, L.Y., Wang, K., Yuan, H.X., LI, H.L., LI Y. (2021): Identification of pathogenic species of three root-lesion nematodes samples from corn fields in Henan Province. Acta Phytopathol Sin, 51: 536 - 548. DOI: 10.13926 /j. cnki. Apps.000541
Xu, Z.P., LI, H.X., LIU, Y.J., LI, W.H., Zhang, S.L. (2020): First report of cyst nematode (Heterodera elachista) on zea mays in gansu province, China. Plant Dis, 105: $511-511$

Yu, J., JIN, X.X., QIN, M., Wu, W.J., XU, C.L., XIE, H. (2017): Identification and description of three species of genus Pratylenchus from crops in Tibet. J Huazhong. Agri. Uni, 36: 20 - 24. DOI: 10.13300/j. cnki.hnlkxb.2017.05.004 